\title{
Vehicle Tracking, Monitoring and Alerting System: A Review
}

\author{
Sumit S. Dukare \\ Department of E\&TC \\ GF's Godavari collage of Engg. \\ Jalgoan (India)
}

\author{
Dattatray A. Patil \\ Department of E\&TC \\ GF's Godavari collage of Engg. \\ Jalgoan (India)
}

\author{
Kantilal P. Rane \\ Department of E\&TC \\ GF's Godavari collage of Engg. \\ Jalgoan (India)
}

\begin{abstract}
The goal of this paper is to review the past work of vehicle tracking, monitoring and alerting system, to categorize various methodologies and identify new trends. Vehicle tracking, monitoring and alerting system is challenging problem. There are various challenges encounter in vehicle tracking, monitoring and alerting due to deficiency in proper real time vehicle location and problem of alerting system. GPS (Global Positioning System) is most widely used technology for vehicle tracking and keep regular monitoring of vehicle. The objective of tracking system is to manage and control the transport using GPS transreceiver to know the current location of vehicle. In number of system, RFID (Radio Frequency Identification) is chosen as one of technology implemented for bus monitoring system. GSM (Global System for Mobile Communication) is most widely used for alerting system. Alerting system is essential for providing the location and information about vehicle to passenger, owner or user.
\end{abstract}

\section{General Terms}

Vehicle Tracking, Vehicle Monitoring, Alerting system

\section{Keywords}

Global Positioning System, Radio Frequency Identification, Global System for Mobile Communication

\section{INTRODUCTION}

Transport is one of the important infrastructures of any country. The main problem about the transportation is the uncertainty of waiting time due to traffic jams and any other issue live abnormal conditioning. The safety of private and public vehicles is a major concern so GPS vehicle tracking system ensures their safety while travelling. In the existing system, different tracking techniques are used such as integration with Google maps, Automatic transit directions or real time tracking and arrival time prediction. Radio Frequency Identification is wireless identification technology that has been used in many fields including solid state monitoring, human, object and animal. The implementation of RFID in any identification and monitoring system can improve the monitoring system can improve the monitoring system and improve the overall performance of system with low cost. Alerting system uses GSM or GPRS for sending information, GSM is mostly used as compared to the GPRS. GSM is used to inform the user about exact location of vehicle.

\section{VEHICLE TRACKING}

Global Positioning System is mostly used for tracking system. In this survey we have studied various tracking system. Benjamin Coifman, David Beymer, et al. proposed a real time computer vision system for vehicle tracking and traffic surveillance on the basis of video image processing system. The vehicle trajectory is used as input to sophisticated, automated surveillance applications. The tracking system can give exact position of vehicle and vehicle movements in weaving sections [1]. Akande Noah Oluwatobi represent automatic vehicle location is advanced method to track and monitor any vehicle equipped with software unit that receives and transfers signal through GPS satellite. Automatic vehicle location system used web based, mobile communication and SMS based platform for communication. This system enables to collect and analyze the information about location of vehicle in real time [2]. Bus arrival time prediction algorithm combines global positioning system with the real time estimates of inter station speed. This system is capable of tracking a large number of buses simultaneously and detects the routes and directions automatically. Artificial neural network model is used for predicting bus arrival times and demonstrate its superior performance as compared with other method [6].

Muhammad Rauf and Nik M. Kamal proposed an intelligent GPS navigation system. In this system neural network is used to process uncorrected raw signals received by GPS receiver. A neural network having an input receiving the satellite related information to obtain an output signal representative of receiver related navigation information, where in the neural network comprises one of the adaptive learning for the error reduction and optimum calculation. This system improves the average accuracy of GPS signal reception at the bus station [8]. The real time bus monitoring system consists of GPS module installed on the buses which transmit the real time location of bus to receiver boards installed on the bus stops. The GPS data of the bus locations is send to centralized control unit and it activating LEDs in the approximate geographic positions of buses on the route. The device will be portable and sustainable; it will not require an external power source and eliminate long term energy costs [19].

\section{VEHICLE MONITORING}

The monitoring system of a vehicle is integration of RFID technology and tracking system. Ben Ammar Haten and Haman Habib proposed bus management system; integration of RFID and WSN will facilitate the extension of an RFID network eliminating the need of wired installation. The system is suitable for monitor bus traffic inside spacious bus stations and can inform administrators whenever the bus is arriving on time, early or late and information is then displayed on the different wireless displays inside and outside the bus station [10]. Kumar Yelamarthi, Daniel Hass, et al. overcome the previous system and develops a system for navigation assistance to visually impaired people. Portable 
terminal unit is an embedded system having RFID reader, GPS and analog compass as input device to obtain location and orientation. In navigation mode start robot reaches destination by avoiding obstacles using ultrasonic and infrared sensor inputs [11]. Ramesh Gardi, Ankita Chavan, et al. proposed land vehicle application on android platform. A land vehicle tracking system combines the installation of an electronic device in vehicle with purpose designed computer software at least at one operational base to enable the owner to track vehicles location. The vehicle information can be viewed on electronic map via internet or specialized software [18]. Thomas Gerlich, James Biagioni, et al. proposed the automatic transit tracking, mapping, and arrival time prediction system based on Google map application which is installed on Smartphone. This level of automation is possible through a set of algorithms that uses GPS traces collected from transit vehicle to determine routes served, locate stops and predict the arrival time at upcoming stops [14].

Almomani, I. M. Alkhalil, N. Y. proposed system which is useful for operators to monitor driving behavior employees. The tracking system includes acquiring the location \& ground speed of vehicle in the current movement. This system receives SMS alert when as vehicle exceeds the pre defined limits by using global system for mobile communication [15]. The real time query system for public transport service using Zigbee and RFID is more competent and suitable for passengers demand and give data such as bus location, bus number and number of persons inside the bus in real time. This system is an efficient and low cost method for intelligent transport system [27]. The public transport network is difficult to use when the user is unfamiliar with the area they are travelling. In such situation, on trip navigation information can substantially ease of use of public transportation. Location based services are increasingly important for modern mobile devices such as a Smartphone. The realized system tracks prediction targets equipped with GPS enabled devices [37].

\section{VEHICLE TRACKING, MONITORING AND ALERTING}

Numerous approaches to vehicle tracking, monitoring and alerting system has been proposed so far. Ankit Kesharwasni, Vaishali Sadaphalt proposed system to overcome problem of public transportation. Wireless sensor network used for monitoring of bus transportation system and record of arrival time of buses at bus stops. The system is detecting the delay and arrival time of bus at bus stops [3]. Kunal Maurya, Mandip Singh and Neelu Jain proposed an anti theft tracking system. Vehicle tracking system is real time system which is working on the GPS and GSM technology which provide the location of vehicle to the vehicle owner in the case of vehicle is stolen. It can also be used in wildlife tracking, asset tracking and in stolen vehicle recovery [4]. Xing Jianping, Zhang Jun, et al. proposed GPS real time vehicle alarm monitoring and alerting system used GPRS and CSD on the embedded system. Compared with the conventional single mode of GPRS, this method makes up the disadvantage of the high time delay and the incertitude of the time delay in data transmission [5]. Transportation is a very important shared resource that enabling efficient and effective use of resources like GSM modem and GPS unit that can be installed on a vehicle and used to track its location. This system is located on the bus and GSM modem communicates via SMS with a server connected to a basic GSM phone [7].

Y. Kakuda proposed technology for children tracking system to prevent crimes against children and beneficial to parents. The technology is based on mobile ad hoc network. The system is helpful to parent to know the safety level and to and from information of students on school route [9]. Farooq, U. M. Amar, M.U. et al. proposed GPS-GSM integrated public transportation management systems consist of four modules such as bus station, in bus, base station and bus stop module. The developed system is useful for facilitating people using public transportation services [12]. Communication between the system and children will be solved by children having tag that transmit information to the bus unit making it possible for system and driver to know the child is on the way to the bus. This system is useful for handling safe route planning school bus position tracking and monitoring [13].

R. Anil kumar, G, Jyothirmai and K. Rameshbabu Proposed Vehicle positioning System Based on ARM with combination of GPS and GSM can upload the information of the vehicle such as the position and speed to the Monitoring center in time and make it convenient to control the traffic. The vehicle position system has advantage of small size, scalable, reliable and powerful expansibility [16]. Intelligent system is able to act according to its situation without having to be instructed by humans. It consists of data processor like artificial neural network, which is usually used as data trainer. The bus monitoring and management system provide the exact location of the bus and predict the arrival time on the basis of route and traffic [17]. V. Venkatakrishnan and R. Seethalakshmi develop Public transport ticketing and monitoring system consists of GPS, GSM, RFID and Zigbee for the users. The use of GSM and GPS technologies allows the system to track vehicle and provides up to date information about ongoing trips. The Zigbee module is interfaced with microcontroller which is used to send the bus information to bus stops and to get information to bus stops. The bus module operates the RFID for ticketing purposes and IR sensor for counting the number of entering and exiting passengers [20]. Prafull Patinge and N.R. Kolhare proposed smart on board public information system, having fix GPS, GSM/GPRS and microcontroller module on bus. This system alert passenger about the present and next station on comparison with GPS coordinates and already stored GPS coordinates of respective location on LCD display in bus and also announcement using speaker [21]. Abid Khan and Ravi Mishra proposed the system consists of single board embedded system having GPS and GSM modems with ARM processor is installed in the vehicle to track vehicle. This system has many advantages such as large capability, low operation cost, strong expansibility [22].

M. A. Hannan, A. M. Mustapha, et al. proposed intelligent bus system develop for campus bus identification monitoring and management system using RFID and sensing technologies like GPS, GPRS and GIS. The ability of this system is that it reduces manpower required at monitoring center. Bus drivers will also be more punctual to the bus schedules that have been established [23]. J. Saranya and J. Selvakumar proposed the system which is focus on implementing children tracking system on android terminal for every child attending in the school. The system includes tracking the child's movement to and from school and information is send to parents and control room. The system consist of voice recognizing sensor which senses the cry of children in the school bus and send information to their parents approximately by using database stored in the system [24]. Swati Chandurkar, Sneha Mugade, et al. proposed real time bus monitoring and passenger information system. The system gives current location of buses and estimates their arrival time at different stops in their respective routes. The system uses link updater locates the bus 
position along the current route of the bus. The estimated time of arrive is updated to control unit and distributes this information to passengers using display board at bus stops [25]. Madhu Kumar, K. Rajashekhar, et al. proposed, Design of punctuality enhanced bus transportation system using GSM and zigbee. In this way service quality of operational efficiency is improved and passenger is also able to get the information about the respective bus [28].

Hoang Dat Pham, M. Drieberg, et al. proposed vehicle tracking system demonstrates the feasibility of real time tracking of vehicle and improved customizability and global operability. The system will provide users with the capability to track vehicle remotely through the mobile network [29]. The tracking system can inform the location and route travelled by vehicle and that information can be observed from any other remote location. The system also includes the web application that provides exact location of target. This system enables to track target in any weather conditions [30]. R. Maruthi and C. Jayakumari proposed SMS based bus tracking system using open source technologies. The system manage and control the transport using a tracking device to known the scheduled vehicle and current location of vehicle via SMS using GPS tracking device. An alert can also be sending to notify the updated location to the users through SMS [31].

V. Yamuna, G. Rupavani, et al. proposed GNSS based bus monitoring system. The main objective of this system is to reduce the waiting time of passenger in bus stop by sending information about the location of buses to the passenger through SMS. Fig.1 shows block diagram of GNSS based bus monitoring system. GNSS based web application is developed which provide which provide real time location of bus on Google Maps along with speed [32]. Hemin Jose and Lekshmy Harikrishnan proposed vehicular system provides information regarding the vehicle such a velocity and position

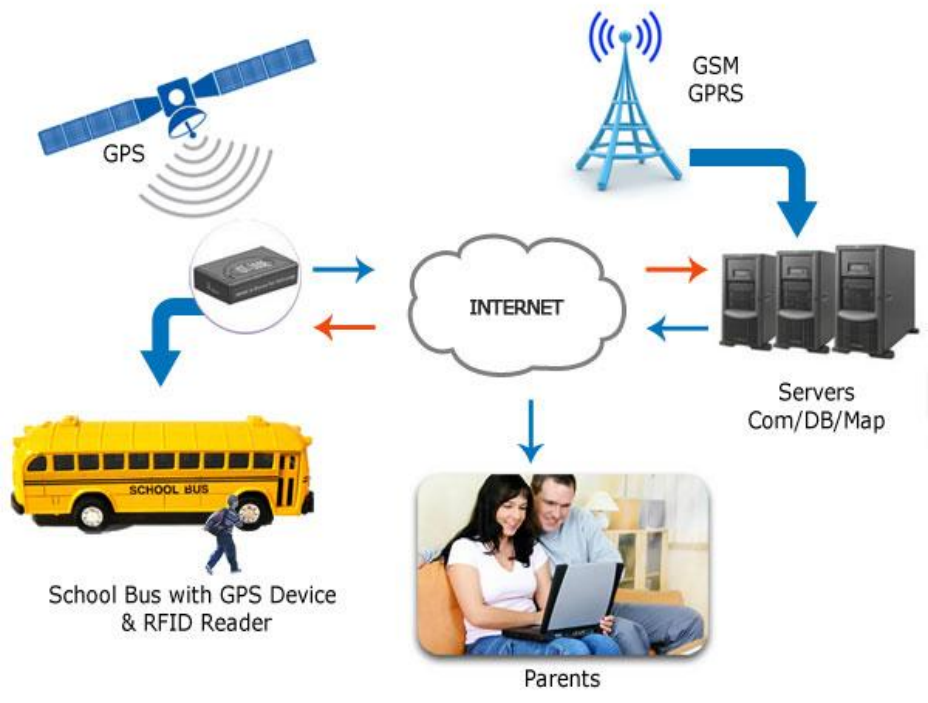

Fig.1: Block Diagram of GNSS based Bus Monitoring System through GPS module and identifying of vehicle to monitoring station and mobile according to definite event stored in a program from monitoring station. This system is also can be interfaced with Vehicle airbag system such that when the sensors detect the accident, the air bags get opened [33]. The real time bus monitoring and passenger information bus tracking device is standalone system is designed to display the real time location of buses in metropolitan city. The system is enable the tracking device to obtain GPS data of bus location and then it is transferred to centralized control unit by using GSM and then transmitted to bus stop and displayed on digital display on bus stops [34].

R. Manikandan and S.Niranjani implement real time public transportation information using GSM query response system. The system is capable of a tracking large number of buses simultaneously, detect their service routes and predict arrival time to down station with an acceptable accuracy. The microcontroller acquires data from the GPS module and sends to the control point by using the GSM module [35].

Gangadhar, M. Madhu, M. S. et al. proposed system provides information of vehicle like position, speed through GPS receiver and temperature to a monitoring system. It also provides security to vehicle by locking engine from remote location using GSM. It also provides security to personal vehicles like car by locking the vehicle engine from remote location using GSM in case of theft. The vehicle can be identified and stopped at anywhere [36]. G. Raja, G. V. Karthik, et al. proposed bus position monitoring system to facilitate the passenger. The wireless communication technologies like GSM \& GPS are used to send the information about number of seats available in the bus to bus station and current location of bus on the route respectively. Real time passenger information system uses variety of technologies to track the location of bus in real time and generate the prediction of bus arrival at stops along the routes [38].

\section{REVIEW ANALYSIS}

After studying various methods adopted by various authors it is observed that numerous methods are used for vehicle tracking, monitoring and alerting system. The existing systems are used for tracking, monitoring and alerting of vehicle for car, truck, cargo, bus, and bike.

The car and bike needed the system to know the real time location of car / bike to owner for safety purpose and to avoid theft of vehicle and alert the owner. The cargo uses real time tracking and monitoring system. For bus, it is used for real time tracking of bus, monitor passenger in to the bus, predict arrival time and send information to the base station. The public transportation uses tracking and monitoring of the bus for arrival time prediction of bus on the respective stops.

The existing system used different technology and method as per application. The study comparison between existing systems is given in Table 1. The table shows the comparison of existing on the basis of parameter used in the system. It give the total review of the existing system used for vehicle tracking, monitoring and alerting system. 
Table 1: Study and comparison between existing systems

\begin{tabular}{|c|c|c|c|}
\hline $\begin{array}{l}\text { Existing } \\
\text { system }\end{array}$ & $\begin{array}{c}\text { Platform / } \\
\text { Technology }\end{array}$ & $\begin{array}{c}\text { Methodolo } \\
\text { gy }\end{array}$ & Comment \\
\hline $\begin{array}{c}\text { Bus } \\
\text { transportation } \\
\text { system using } \\
\text { Wireless } \\
\text { Sensor } \\
\text { Network [3], } \\
{[28]}\end{array}$ & $\begin{array}{l}\text { PC based } \\
\text { system. WSN } \\
\text { are used to } \\
\text { monitor the } \\
\text { system }\end{array}$ & $\begin{array}{l}\text { Location } \\
\text { analysis, } \\
\text { sending } \\
\text { information } \\
\text { to server }\end{array}$ & $\begin{array}{l}\text { The } \\
\text { system is } \\
\text { complex. }\end{array}$ \\
\hline $\begin{array}{c}\text { Children } \\
\text { tracking } \\
\text { system [9], } \\
{[24]}\end{array}$ & $\begin{array}{c}\text { GPS, Mobile ad } \\
\text { hoc network, PC } \\
\text { based system }\end{array}$ & $\begin{array}{l}\text { Children } \\
\text { tracking } \\
\text { and data } \\
\text { analysis }\end{array}$ & $\begin{array}{c}\text { The } \\
\text { system is } \\
\text { easily } \\
\text { upgrade. }\end{array}$ \\
\hline $\begin{array}{c}\text { Public } \\
\text { transport } \\
\text { management } \\
\text { services [12], } \\
{[20]}\end{array}$ & $\begin{array}{c}\text { Microcontroller } \\
\text { and PC based } \\
\text { system. }\end{array}$ & $\begin{array}{c}\text { GPS } \\
\text { tracking, } \\
\text { sending } \\
\text { alert } \\
\text { message }\end{array}$ & Complex \\
\hline $\begin{array}{c}\text { Intelligent bus } \\
\text { monitoring \& } \\
\text { management } \\
\text { system [17], } \\
\text { [39] }\end{array}$ & $\begin{array}{c}\text { RFID, GPS, } \\
\text { GSM, PC based } \\
\text { system. }\end{array}$ & $\begin{array}{c}\text { GPS } \\
\text { tracking, } \\
\text { Database } \\
\text { collection, } \\
\text { alerting }\end{array}$ & $\begin{array}{c}\text { User } \\
\text { friendly }\end{array}$ \\
\hline $\begin{array}{c}\text { On board } \\
\text { public } \\
\text { information } \\
\text { system using } \\
\text { GPS \& GSM } \\
\text { for public } \\
\text { transport [21], }\end{array}$ & $\begin{array}{c}\text { GPS, } \\
\text { GSM/GPRS, PC } \\
\text { based system. }\end{array}$ & $\begin{array}{c}\text { GPS } \\
\text { tracking, } \\
\text { control } \\
\text { using map } \\
\text { and } \\
\text { sending } \\
\text { alert SMS. }\end{array}$ & $\begin{array}{c}\text { User } \\
\text { friendly }\end{array}$ \\
\hline $\begin{array}{c}\text { GPS-GSM } \\
\text { based tracking } \\
\text { system with } \\
\text { Google map } \\
\text { based } \\
\text { monitoring } \\
{[22],[30]}\end{array}$ & $\begin{array}{l}\text { GPS, GSM and } \\
\text { microcontroller } \\
\text { based system. }\end{array}$ & $\begin{array}{c}\text { GPS } \\
\text { tracking, } \\
\text { monitoring } \\
\text { using } \\
\text { Google } \\
\text { map and } \\
\text { alerting }\end{array}$ & $\begin{array}{c}\text { The } \\
\text { system is } \\
\text { user } \\
\text { friendly. }\end{array}$ \\
\hline $\begin{array}{c}\text { GNSS based } \\
\text { bus } \\
\text { monitoring \& } \\
\text { sending SMS } \\
\text { to passenger } \\
{[26],[32]}\end{array}$ & $\begin{array}{l}\text { PC based } \\
\text { system. }\end{array}$ & $\begin{array}{c}\text { RFID } \\
\text { monitoring, } \\
\text { location } \\
\text { tracking } \\
\text { and alerting }\end{array}$ & $\begin{array}{c}\text { The } \\
\text { system is } \\
\text { easy to } \\
\text { upgrade. }\end{array}$ \\
\hline $\begin{array}{c}\text { Vehicle } \\
\text { tracking and } \\
\text { monitoring } \\
{[36]}\end{array}$ & $\begin{array}{l}\text { System is based } \\
\text { on ARM7 } \\
\text { microcontroller. }\end{array}$ & $\begin{array}{l}\text { Tracking, } \\
\text { temperature } \\
\text { sensing and } \\
\text { alerting }\end{array}$ & $\begin{array}{l}\text { The } \\
\text { system is } \\
\text { user } \\
\text { friendly. }\end{array}$ \\
\hline
\end{tabular}

In bus transportation system, WSN improves transportation system performance but problem is short range of transmission of information. Zigbee have short range of data transmission [28]. In children tracking system, the system have limited functioning, size of student module is big and limited use only [24]. Public transport management system, the circuitry is complex and costly [12]. The processor of system is unreliable with slow speed processing speed and Zigbee have short range of data transmission [20]. The algorithm of system is complex and it may be improve for better performance of system [21]. The system uses tracking on the basis of Google map. It is effective but system has complexity for Google map [22], [30]. The system only monitors the bus but not predict arrival time of time of bus respective stops.

From study and observation we can say that the algorithm, technology of existing system can be improved for better performance and overcome the problem of existing system. The algorithm of GPS tracking can be modified and reduced. The database management system can be improved by latest technology of database management. Monitoring accuracy and efficiency of reader can be increases with high operating frequency and extending the range of reader. The data transmission rate of system can be improved. The processor improves the processing speed of the system. By using the GPS, GSM/GPRS, RFID reader and ARM 11 processor develop better system for vehicle tracking, monitoring and alerting system as compared to existing system. The system is cost effective and user friendly.

\section{CONCLUSION}

In this paper, we have reviewed a various existing techniques of vehicle tracking, monitoring and alerting system. We have studied various technologies, algorithms and methods for tracking, monitoring and alerting system. Every system has its own importance; different authors have tried different methods based on applications. Still there is scope to optimize different methodologies and algorithm to make system more users friendly and wide application areas. For future enhancement, we may develop a vehicle tracking, monitoring and alerting system using combination of RFID system, GPS, GSM/GPRS with high speed processor. The system will have latest technology and optimized algorithm with moderate cost. The system may focus on accurate arrival time prediction and real time position of vehicle. The system can be installed in cargo, trucks, buses, cars and boats.

\section{REFERENCES}

[1] Benjamin Coifman, David Beymer, Philip McLauchlan, Jitendra Malik, "A real-time computer vision system for vehicle tracking and traffic surveillance," Transportation research part C6, 1998.

[2] Akande Noah Oluwatobi, "A GPS based automatic vehicle location system for bus transit," 1999.

[3] Ankit Kesharwani, Vaishali Sadaphal, Maitreya Natu, "Empowering bus transportation system using wireless sensor networks," 2000.

[4] Kunal Maurya, Mandeep Singh, Neelu Jain, "Real time tracking system using GSM and GPS technology - an anti theft tacking system," International Journal of Electronics and Computer Science Engineering, volume 1, number 3, 2006. 
[5] Xing Jianping, Zhang jun, Cheng Hebin, Li Changging, Shi xiaohui, "GPS real time vehicle alarm monitoring system base on GPRS and CSD using the embedded system," International Conference on ITS Telecommunications, 2006.

[6] Dihua Sun, Hong Luo, Liping Fu, Weining Liu, “ Predicting bus arrival time on the basis of Global Positioning System data," Transportation Research Board of the National Academies, Washington, D.C.,2007, pp:67-72, 2007.

[7] R. E. Anderson, A. Poon, C. Lustig, W. Brunette, G. Borriello, "Building a transportation system using only GPS and SMS infrastructure," International Conference on Information and Communication Technologies and Development (ICTD), pp: 233-242, 2009.

[8] Muhammad Rauf, Ahmed N. Abdalla, Nik M. Kamal, Azher Fakhruddin, "Design of intelligent GPS system navigation for bus monitoring and station reporting," National Conference on Postgraduate Research (NCONPGR), 2009.

[9] Y. Kakuda, T. Ohta, S. Inoue, F. Kohno, Y. Akiyama "Performance improvement of Hiroshima city tracking system by correction of wrong registration on school

routes," International Symposium on Autonomous System, pp: 261-266, March 2009

[10] Ben Ammar Haten, Haman Habib, "Bus management system using RFID in WSN," European and Mediterranean Conference on Information System, 2010.

[11] Kumar Yelamarthi, Daniel Haas, "RFID and GPS integrated navigation system for the visually impaired," 2010 .

[12] Farooq, U. M. Amar, M. U. Asad, A. Iqbal, "GPSGSM integration for enhancing public transportation management services," 2010 International Conference on Computer Engineering and Applications, Volume 2, pp: 142-147, March 2010.

[13] A. Viklind, "Experience from an application for safe transport to and from school: a step toward SAFEWAY2SCHOOL," International Conference on Telecommunications, 2011.

[14] James Biagioni, Tomas Gerlich, Timothy Merrified, Jakob Eriksson, "Easy tracker: automatic transit tracking, mapping and arrival time prediction using smartphone," Journal of the Transportation Research Board of the National Academies, 2011.

[15] Almomani, I. M. Alkhalil, N. Y. Ahmad, E. M. Jodeh, R. M. "Ubiquitous GPS vehicle tracking management system," IEEE Jordan Conference on Applied Electrical Engineering and Computing Technologies, pp: 1-6, December 2011

[16] R. Anil Kumar, G. Jyothimai, K. Rameshbabu, "Design and development of ARM based embedded intelligent public transport vehicle position system," International Journal of Internet Computing, Vol-1, Issue 3, 2012.

[17] Mahammad Abdul Hannan, Aishah Mustapha, Aini Hussain, "RFID and communication technologies for an intelligent bus monitoring and management system," Turkish Journal of Electrical Engineering and Computer Science, pp: 106-120, 2012.
[18] Ramesh Chandra Gadri, Ankita Chavan, Reema Sonawane, "Land vehicle tracking application on android platform," International Journal of Engineering Research and Applications, Vol. 2, Issue 3, pp: 1978-1982, MayJun 2012.

[19] Dr. Saylee Gharge, Manal Chhaya, Gaurav Chheda, Jitesh Deshpande, "Real time bus monitoring system using GPS," An International Journal of Engineering Science and Technology, Vol. 2, Issue 3, June 2012.

[20] V. Venkatakrishnan, R. Seethalakshmi, "Public transport ticketing and monitoring system," Journal of Theoretical and Applied Information Technology, Vol. 38, No.1, April 2012.

[21] Prafill D. Patinge, N. R. Kolhare, "Smart onboard public information system using GPS and GSM integration for public transport," International Journal of Advanced Research in Computer and Communication Engineering, Vol. 1, Issue V, July 2012

[22] Abid Khan, Ravi Mishra, "GPS-GSM based tracking system," International Journal of Engineering Trends and Technology, Vol. 3, Issue 2, pp: 161-164, 2012.

[23] M. A. Hannan, A. M. Mustapha, A. Hussain, H. Basri, “ Intelligent bus monitoring and management system," Proceeding of the World Congress on Engineering and Computer Science, Vol. II, October 24-26, 2012.

[24] J. Saranya, J. Selvakumar, "Implementation of children tracking system on android mobile terminals," International Conference on Communication and Signal Processing, April 3-5, 2013.

[25] Swati Chandurkar, Sneha Mugade, Sanjana Sinha, Pooja Borkar, "Implementation of real time bus monitoring and passenger information system," International Journal of Scientific and Research Publications, Vol. 3, Issue 5, May 2013.

[26] G. Lavanya, Preethy, W. Shameem, A. Sushmitha, R. "Passenger bus alert system for easy navigation of blind," International Conference on Circuits, Power and Computing Technologies [ICCPCT-2013], 2013.

[27] S. P. Manikandan, P. Balakrishnan, "An Efficient real time query system for public transportation service using Zigbee and RFID," International Journal of Research in Communication Engineering, Vol. 2, No. 2, June 2012.

[28] Madhu Manikya Kumar, K. Rajesekhar, K. Pavani, "Design of punctually enhanced bus transportation system using GSM and Zigbee," International Journal of Research in Computer and Communication Technology, Vol. 2, Issue 12, December 2013

[29] Hoang Dat Pham, M. Drieberg, Chi Cuong Nquyen, "Development of vehicle tracking system using GPS and GSM modem," IEEE Conference on Open System, pp: 89-94, 2013.

[30] Pankaj Verma, J. S. Bhatia, "Design and development of GPS-GSM based tracking system with Google map based monitoring," International Journal of Computer Science, Engineering and Applications, Vol. 3, No.3, June 2013.

[31] R. Maruthi, C. Jayakumari, "SMS based bus tracking system using open source technologies," International 
Journal of Computer Application, Volume 86, No 9, January 2014.

[32] N. Vijayalashmy, V. Yamuna, G. Rupavani, A. Kannaki@VasanthaAzhagu,“ GNSS based bus monitoring and sending SMS to the passengers," International Journal of Innovative Research in Computer and Application Engineering, Vol. 2, Special Issue 1, March 2014.

[33] Hemin Jose, Lekshmy Harikrishnan, "A Review on vehicular monitoring and tracking," IOSR Journal of Electronics and Communication Engineering (IOSRJESE), Volume 9, Issue 3, Ver. 1, pp: 20-23, (May-Jun) 2014.

[34] Janarthanan, B. Santhanakrishnan, T. "Real time metropolitan bus position in system design using GPS and GSM," International Conference on Green Computing Communication and Electrical Engineering (ICGCCEE), pp: 1-4, 2014.

[35] R. Manikandan, S. Niranjani, "Implementation on real time transportation information using GSM query response system," Contemporary Engineering Sciences, Vol. 7, No.11, pp: 509-514, 2014

[36] Gangadhar, M. Madhu, M. S. Pushpalata, S. "Vehicle tracking and monitoring by ARM 7," SSRG International Journal of Electrical and Electronics Engineering (SSRG-IJEEE), Volume 1, Issue 4, June 2014.

[37] Pradip Suresh Mane, Vaishali Khairnar, "Analysis of bus tracking system using GPS on smart phones," IOSR Journal of Computer Engineering (IOSR-JCE), Volume 16, Issue 2, Ver.XII, pp: 80-82, 2014.

[38] G. Raja, D. NaveenKumar, G. Dhanateja, G. V. Karthik, Y. Vijay Kumar, "Bus Position monitoring system to facilitate the passengers," International Journal of Engineering Science and Advanced Technology(IJESAT), Volume-3, Issue-3, pp: 132-135, 2014.

[39] S. Eken, A. Sayar, "A Smart bus tracking system based on location aware services and QR codes," IEEE International Symposium on Innovations in Intelligent and Applications Proceedings, pp: 299-309, 2014 